\title{
The late radiotherapy normal tissue injury phenotypes of telangiectasia, fibrosis and atrophy in breast cancer patients have distinct genotype-dependent causes
}

\author{
G Giotopoulos', RP Symonds",2, K Foweraker², M Griffin ${ }^{3}$, I Peat', A Osman² and M Plumb' \\ 'Department of Genetics, University of Leicester, Leicester LEI 7RH, UK; ${ }^{2}$ Department of Cancer Studies and Molecular Medicine, University of Leicester, \\ Level 2, Osborne Building, Leicester Royal Infirmary, Leicester LEI 5WW, UK; ${ }^{3}$ Department of Oncology, Nottingham University Hospitals NHS Trust, \\ CITY Hospital Campus, ICT Services, Hucknall Road, Nottingham, UK
}

\begin{abstract}
The relationship between late normal tissue radiation injury phenotypes in 167 breast cancer patients treated with radiotherapy and: (i) radiotherapy dose (boost); (ii) an early acute radiation reaction and (iii) genetic background was examined. Patients were genotyped at single nucleotide polymorphisms (SNPs) in eight candidate genes. An early acute reaction to radiation and/or the inheritance of the transforming growth factor- $\beta$ I (TGF $\beta$ I -509T) SNP contributed to the risk of fibrosis. In contrast, an additional I 5 Gy electron boost and/or the inheritance of X-ray repair cross-complementing I (XRCCI) (R399Q) SNP contributed to the risk of telangiectasia. Although fibrosis, telangiectasia and atrophy, all contribute to late radiation injury, the data suggest that they have distinct underlying genetic and radiobiological causes. Fibrosis risk is associated with an inflammatory response (an acute reaction and/ or TGF $\beta$ I), whereas telangiectasia is associated with vascular endothelial cell damage (boost and/or XRCCI). Atrophy is associated with an acute response, but the genetic predisposing factors that determine the risk of an acute response or atrophy have yet to be identified. A combined analysis of two UK breast cancer patient studies shows that $8 \%$ of patients are homozygous (TT) for the TGF $\beta$ I (C-509T) variant allele and have a I5-fold increased risk of fibrosis following radiotherapy (95\% confidence interval: 3.76$60.3 ; P=0.000003$ ) compared with (CC) homozygotes.

British Journal of Cancer (2007) 96, I00 I-1007. doi: I0.1038/sj.bjc.6603637 www.bjcancer.com
\end{abstract}

Published online 27 February 2007

(c) 2007 Cancer Research UK

Keywords: breast cancer; radiation injury; TGF $\beta$ I; $\mathrm{XRCCl}$; fibrosis; telangiectasia

Radiotherapy is associated with a wide spectrum of normal-tissue reactions, and as the life expectancy of cancer patients increases, normal tissue effects are increasingly of clinical importance. Tissue toxicity may range from asymptomatic changes in tissue structure and function, to severe cosmetic disfigurement and life-altering changes in organ function (Bentzen et al, 2003). The effects can be divided into early/acute reactions, which occur within 90 days of treatment, and late reactions that occur more than 90 days after treatment and can persist for life (Van der Kogel, 1993).

Early reactions principally affect high turn-over tissues, such as skin, the gastrointestinal tract and bone marrow where the onset and severity of the reactions reflect the balance between the rate of stem/progenitor-cell killing and the rate of regeneration of surviving cells (Van der Kogel, 1993). Severe acute reactions are rare and have been associated with syndromes such as Ataxia Telangiectasia and Nijmgen Breakage syndrome that have inherited highly penetrant and mutant alleles encoding DNA repair enzymes, although low penetrance alleles in the general population have also been implicated in cellular radiosensitivity

*Correspondence: Dr RP Symonds; E-mail: rps8@le.ac.uk Received 15 November 2006; revised 19 January 2007; accepted 23 January 2007; published online 27 February 2007
(Hu et al, 2001; Moullan et al, 2003; Chang-Claude et al, 2005; Fernet and Hall, 2005).

Late effects typically, but not exclusively, manifest in low turnover tissues such as lung, heart, liver and the nervous system that are comparatively depleted of stem and progenitor cells. Common late manifestations include fibrosis, telangiectasia and atrophy, and a particular tissue or organ may show signs of one or more of these reactions at different times following the radiotherapy (O'Sullivan and Levin, 2003). A significant number of patients ( $\sim 5 \%$ ) show late normal tissue damage, so there are presumably genetic component(s) that contribute(s) to the risk and severity of the late tissue radiation effects in the general population.

Transforming growth factor- $\beta 1$ (TGF $\beta 1$ ) is the major cytokine responsible for the regulation of fibroblast proliferation and differentiation (Randall and Coggle, 1995; Gauldie et al, 2003; O'Sullivan and Levin, 2003). Differentiated fibroblasts synthesise the collagens and proteoglycans in the extracellular matrix, and it has been suggested that an increase in these fibroblasts may cause the fibrotic phenotype (Mauch and Kreig, 1990; Martin et al, 2000; O'Sullivan and Levin, 2003). Radiation induces long-term TGF $\beta 1$ overexpression probably owing in part to oxidative stress and an inflammatory response (Randall and Coggle, 1995; Anscher et al, 1997; Martin et al, 1997, 2000; O'Sullivan and Levin, 2003), and a causal relationship between increased TGF $\beta$ production and the 
development of tissue fibrosis has been reported in animal models (Zugmaier et al, 1991; Terrell et al, 1993; Sanderson et al, 1995; Clouthier et al, 1997). Most significantly, elevated serum TGF $\beta 1$ levels were correlated with an increased risk of fibrosis in breast and lung cancer patients (Awad et al, 1988; Anscher et al, 1997; Grainger et al, 1999; Li et al, 1999) and a comparison of the genotypes of unaffected and affected patients has been genetically associated with functional polymorphisms in the TGF $\beta 1$ gene (Awad et al, 1988; El-Gamel et al, 1999; Quarmby et al, 2003; Andreassen et al, 2005).

Whether the late tissue effects such as fibrosis, atrophy and telangiectasia are biologically or radiobiologically related is controversial. The observation that normal tissue damage can involve one or combinations of these phenotypes suggests that their underlying causes may be different. The power of genetic studies seeking to associate a genotype with a phenotype is absolutely dependent on the precise definition of the phenotype. Several scales have been developed, which allow recording of such injury uniformly and reproducibly, and include the Radiation Therapy Oncology Group (RTOG) scales, which are relatively simple to score as each site treated with radiotherapy scores $0-5$ according to the degree of injury incurred with an extreme score of 5 indicating patient death (Cox et al, 1995).

The Late Effects of Normal Tissue-Subjective Objective Management Analytical (LENT-SOMA) scale allows comparison between individuals of the clinical perception of injury, the patient's perception of the injury, the medical management required and the underlying pathological process (Pavy et al, 1995). A score of 0-4 is given to each of the LENT-SOMA tests, and the sum of the individual scores for each patient a measure of overall tissue damage. However, the Objective analyses in LENT-SOMA include separate quantitative measures of fibrosis, atrophy and telangiectasia, so LENT-SOMA provides a more detailed and specific description of the nature (phenotype) and severity of the injury/ies than the RTOG scale.

In this report, we have carried out a genetic association study on breast cancer patients at least 4 years after radiotherapy treatment who were scored for normal tissue damage using both RTOG and SOMA scales. The patients were also scored for an early acute reaction to radiotherapy within 90 days of treatment, and whether or not they received a $15 \mathrm{~Gy}$ electron boost. Patients were genotyped for functional single nucleotide polymorphisms (SNPs) in eight candidate genes, and thus enabled the analysis of the relative contribution of radiotherapy schedule, the presence of an early acute response and genetic background, to the risk of specific late injury phenotypes.

\section{MATERIALS AND METHODS}

\section{Patients and methods}

The study has been undertaken with the participation of patients attending the oncology departments of Leicester Royal Infirmary,
Glenfield Hospital, Leicester and Nottingham City Hospital, UK. Full ethical and local trust approval was obtained from the relevant ethics committees and trust Research and Development departments. All patients gave written informed consent before entry into the study, and underwent an examination of the affected area and the recognised features of late radiation effects scored by the SOMA and/or RTOG scales. Seven patients refused to take part in the study.

Tumour-free breast cancer patients were recruited sequentially in the follow-up clinic of one consultant in Leicester, UK (IP). The majority $(155 / 167)$ were treated more than 4 years previously (median $=6.1$ years), but 12 additional patients who were known to have late effects were examined at the City hospital, Nottingham $(n=5)$, and the Leicester Royal Infirmary $(n=7)$, UK between 2.3 and 3.6 years after treatment. All patients were asked about potential radiosensitising comorbid diseases such as diabetes or collagen vascular disorders and a family history of abnormal reactions to radiotherapy. Initial surgery was either a lumpectomy $(n=116)$ or mastectomy plus axillary dissection $(n=47)$. Two patients had a lumpectomy but then went on to have a mastectomy, and two had no surgery.

Radiotherapy (6 MV X-rays) was given either after mastectomy or lumpectomy using tangential fields, and all patients received similar field sizes. All patients also had a $1.5 \mathrm{~cm}$ thick strip of wax $4 \mathrm{~cm}$ in width applied to either the lumpectomy or mastectomy scar to reduce 'skin sparing' during every second fraction. A total of 119 patients received the then standard departmental protocol of $45 \mathrm{~Gy}$ in 20 fractions in 4 weeks given to either the breast or chest wall. Seventy-one of these patients who had been treated by local excision received a boost of $15 \mathrm{~Gy}$ in five fractions in 1 week using $8-12 \mathrm{MeV}$ electrons to the site of the lumpectomy. Boost sizes were between $6 \times 6$ and $8 \times 10 \mathrm{~cm}$. Ten patients received $40 \mathrm{~Gy}$ in 15 fractions as part of the START B trial (NCRN Trial Standardisation of Breast Radiotherapy, 1998). Thirty-three patients were treated with a whole breast dose of $50 \mathrm{~Gy}$ in 25 fractions either as part of the START trial or following the publication of the European Organisation of Cancer Radiotherapy and Breast Cancer Groups study (EORTC) (Bartelink et al, 2001), which identified a group of patients (node negative, complete excision aged $<50$ ) who did not require a local boost (Table 1 ). The mean age at treatment was 56.92 (range 30-78).

The majority of patients (157/167) were Caucasians, but nine patients were of Asian descent and one patient of African Caribbean descent. Twenty-seven patients received anthracylinebased chemotherapy (two of which also received CMF), and 18 patients received non-anthracyline-based chemotherapy before radiotherapy, and 151 patients were further treated with tamoxifen (one stopped during treatment).

Twenty-four patients were positive for an acute reaction within 90 days of treatment, and three of these did not complete the radiotherapy schedule. However, including the $15 \mathrm{~Gy}$ boost, only one of the three acute responders received significantly less $(16.73 \mathrm{~Gy})$ than a total $2 \mathrm{~Gy}$ equivalent dose of $40 \mathrm{~Gy}$.

\begin{tabular}{|c|c|c|c|c|c|c|}
\hline Total dose (Gy) & No. of fractions & $\begin{array}{l}2 \text { Gy equivalent } \\
\text { dose }(\alpha / \beta 2)\end{array}$ & Chemotherapy & Tamoxifen & No boost & Boost \\
\hline $15.75^{\mathrm{a}}$ & 7 & 16.73 & 0 & I & 1 & 0 \\
\hline $34^{\mathrm{a}}$ & 17 & 34 & 0 & 0 & 0 & 1 \\
\hline $38^{a}$ & 17 & 40.64 & 0 & 1 & 0 & 1 \\
\hline 40 & 15 & 46.6 & 2 & 10 & 9 & 1 \\
\hline 45 & 20 & 47.81 & 33 & 109 & 48 & 71 \\
\hline 48 & 24 & 48 & 1 & I & 1 & 0 \\
\hline 50 & 25 & 50 & 9 & 29 & 33 & 1 \\
\hline
\end{tabular}

a Patients who did not complete the planned radiotherapy schedule due to a severe early reaction to radiotherapy. 
Sample collection and preparation DNA was collected from the patients for genetic analysis by means of a buccal swab. DNA was extracted from the buccal samples using the QIAamp DNA mini kit (QIAGEN GmbH, Germany), using the standard manufacturers' protocol. DNA was PCR amplified and analysed for QTG restriction fragment length polymorphisms using published PCR primers and PCR conditions, and restriction enzymes: TGF $\beta 1$ (C509T) (Quarmby et al, 2003); X-ray repair cross-complementing 1 (XRCC1; R399Q) and apurinic/apyrimidinic endonuclease (APE-1; D126E) (Hu et al, 2001); dihydrofolate reductase (DHFR; $15 \mathrm{bp}$ intron 1 deletion) (Johnson et al, 2004); the CX3CR1 (G745A) fractalkine receptor (McDermott et al, 2001); epoxide hydrolase (Hyl-1; Y113H) (Lebailly et al, 2002); and methionine synthetase (MS; A2756G) and methylenetetrahydrofolate reductase (MTHFR; C667T) (Linnebank et al, 2004).

Statistical analysis The G-test was used to examine the relationship between genotype and phenotype. The $G$-tests are maximum likelihood statistical significance tests (log-likelihood ratio) using the William's correction for small sample size (Sokal and Rohlf, 1995). Allele frequencies were examined by calculating the odds ratios (OR), with 95\% confidence intervals (95\% CI), for the frequency of the polymorphic allele in one group relative to another.

\section{RESULTS}

A total of 167 breast cancer patients that were treated with radiotherapy were recruited and examined for late normal tissue damage. The objective SOMA scales (0-4) (Pavy et al, 1995) were used to score for fibrosis, atrophy and telangiectasia severity during a detailed physical examination and represent separate phenotypic measures of late normal tissue damage. The SOMA scores of 1 represent subtle examiner-dependent changes that are inconclusive and in this study are either excluded or included in the group of patients that show no signs (SOMA 0) of a particular injury phenotype. In contrast, the SOMA scores of 2-4 represent unambiguous evidence of late tissue injury. Patients were also scored using the comparatively nonspecific RTOG scales, but were non-informative in all the association studies performed (data not shown).

Factors that might influence the risk and severity of late normal tissue damage include anatomical differences between individuals, the initial surgery, treatment regimes (whether or not the patient received chemotherapy or an electron boost), whether the patient had an early acute reaction and whether the individual patient was genetically predisposed. Chemotherapy may increase late effects (Fiets et al, 2003; Shanley et al, 2006) especially anthracycline containing regimens but the number of patients that received anthracyline and non-anthracyline-based chemotherapy in this study is too small for any meaningful statistical analysis to compare the two chemotherapies (Table 1).

\section{Radiation dose}

The majority $(165 / 167)$ of patients received a very similar total 2 Gy dose fraction equivalent (45-50 Gy; Table 1), so dose differences are largely due to whether the patient received an additional $15 \mathrm{~Gy}$ electron boost (18/2 Gy equivalent). The area irradiated in all patients was very similar $(6 \times 6-8 \times 10 \mathrm{~cm})$, and the late injury phenotypes readily scored within that area by sight and/or touch.

Excluding the one patient who received significantly less than $45 \mathrm{~Gy}$ because of a severe acute reaction to radiotherapy (dose $15.75 \mathrm{~Gy}$; Table 1$)$, patients who received a $15 \mathrm{~Gy}$ boost $(n=75)$ were compared with patients who did not receive a boost $(n=91)$ (Table 2). Patients that manifested no signs of late injury (SOMA score 0 ) were compared with patients that clearly showed signs of late tissue injury (SOMA score 2-3). No association between fibrosis and the $15 \mathrm{~Gy}$ boost was observed $(P=0.47)$ and a similar result was obtained for atrophy $(P=0.28$; data not shown). In contrast, the $15 \mathrm{~Gy}$ boost was weakly associated with an increased risk of telangiectasia (OR 2.4; 95\% CI 1.1-5.4; $P=0.033$ ), consistent with clinical evidence that telangiectasia is usually confined to the boost-exposed region of the breast.

\section{Late injury severity and early acute reaction}

Twenty-five patients had an unusually severe acute reaction (erythema, moist desquamation) within 90 days of treatment, so the presence or absence of this early radiation phenotype was compared with the late objective SOMA scores (Table 3). Comparing unaffected patients (SOMA score 0) and clearly affected patients (SOMA score 2-4) indicates that an early acute reaction increases the risk of long-term fibrosis by an OR of 8.5 (95\% CI 2.64-28.5; $P=0.00004)$, and increases the risk of longterm atrophy by 4.7 (95\% CI $1.25-17.64 ; P=0.02)$. Telangiectasia as a late normal tissue injury phenotype was not associated with an early acute reaction.

In conclusion, within the $45-50 \mathrm{~Gy}$ dose range (20-25 fractions) used to treat breast cancer patients in this study, an additional $15 \mathrm{~Gy}$ boost appears to contribute to an increased risk of telangiectasia. Conversely, a boost does not predispose to fibrosis (or atrophy) but an acute reaction does. These findings, which are based on relatively small numbers of patients, are in disagreement with earlier studies of post-mastectomy patients (Bentzen and Overgaard, 1991; Bentzen et al, 1993) and thus need to be independently confirmed.

\section{Genetic association between genotype and phenotype}

Patients were genotyped for eight functional SNPs in candidate genes. All polymorphisms were assessed by PCR amplification of buccal DNA and analysed using established Restriction Fragment Length Polymorphisms (RFLP). Transforming growth factor- $\beta 1$ polymorphisms were confirmed by direct sequencing.

Table 2 Risk of injury phenotypes and the I5 Gy electron boost

\begin{tabular}{|c|c|c|c|c|}
\hline \multirow{2}{*}{$\begin{array}{l}\text { SOMA } \\
\text { score }\end{array}$} & \multicolumn{2}{|c|}{ Fibrosis number of patients } & \multicolumn{2}{|c|}{$\begin{array}{c}\text { Telangiectasia number o } \\
\text { patients }\end{array}$} \\
\hline & No boost & Boost & No boost & Boost \\
\hline 0 & 67 & 47 & 66 & 44 \\
\hline I & 14 & 18 & 10 & 7 \\
\hline 2 & 8 & 8 & | | & 14 \\
\hline 3 & 2 & 2 & 4 & 10 \\
\hline
\end{tabular}

Table 3 Risk of late injury phenotypes and an early acute reaction

\begin{tabular}{|c|c|c|c|c|c|c|}
\hline \multirow[b]{2}{*}{$\begin{array}{l}\text { SOMA } \\
\text { score }\end{array}$} & \multicolumn{2}{|c|}{ Fibrosis (patients) } & \multicolumn{2}{|c|}{$\begin{array}{c}\text { Telangiectasia } \\
\text { (patients) }\end{array}$} & \multicolumn{2}{|c|}{ Atrophy (patients) } \\
\hline & $\begin{array}{c}\text { Not } \\
\text { acute }\end{array}$ & Acute & $\begin{array}{c}\text { Not } \\
\text { acute }\end{array}$ & Acute & $\begin{array}{c}\text { Not } \\
\text { acute }\end{array}$ & Acute \\
\hline 0 & 103 & 12 & 97 & 14 & 99 & 14 \\
\hline I & 29 & 3 & 12 & 5 & 34 & 5 \\
\hline 2 & 8 & 8 & 22 & 3 & 8 & 4 \\
\hline 3 & 2 & 2 & 11 & 3 & 1 & 2 \\
\hline
\end{tabular}

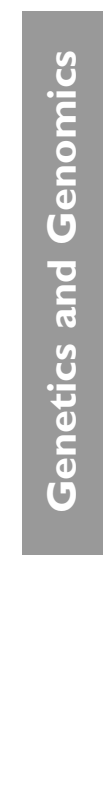


The frequencies of the variant alleles were comparable with those reported in other studies (Hu et al, 2001; McDermott et al, 2001; Lebailly et al, 2002; Quarmby et al, 2003; Johnson et al, 2004; Linnebank et al, 2004), and all SNPs were in Hardy-Weinberg equilibrium (Table 4).

The genes and corresponding SNP were chosen because XRCC1 (R399Q) and APE-1 (D126E) have been implicated in DNA repair (Hu et al, 2001; Chang-Claude et al, 2005; De Ruyck et al, 2005), TGFB1 (C-509T) and CX3CR1 (G745A) have been implicated in inflammation and fibrosis (Zugmaier et al, 1991; Randall and Coggle, 1995; Anscher et al, 1997; Li et al, 1999; Martin et al, 2000; McDermott et al, 2001; Gauldie et al, 2003), MTHFR (C667T), MS (A2756G) and DHFR (19bp del intron 1) involved in folate metabolism (Johnson et al, 2004; Linnebank et al, 2004), epoxide hydrolase $(H y l 1 \mathrm{Y} 113 \mathrm{H})$ implicated in oxidative stress (Lebailly et al, 2002), and XRCC1 (R399Q) have been associated with susceptibility to breast cancer (Moullan et al, 2003). Additionally, several gene polymorphism have previously been implicated in late radiation-induced tissue damage (Awad et al, 1988; El-Gamel et al, 1999; Grainger et al, 1999; Quarmby et al, 2003; Andreassen et al, 2005; De Ruyck et al, 2005, 2006; Brem et al, 2006), and TGF $\beta 1$ and $\mathrm{Hyll}$ are induced following exposure to ionising radiation (Anscher et al, 1997; Martin et al, 1997).

Out of the eight SNP examined, only the TGF 1 1 (C-509T) and XRCC1 (R399Q) polymorphisms showed any significant association with late tissue injury in this study.

\section{Fibrosis and telangiectasia}

Subjective Objective Management Analytical scores for fibrosis and telangiectasia were analysed by comparing clearly affected (SOMA score 2-4) and unaffected patients (SOMA score 0 or $0-1$ ). As shown in Table 5, the TGF $\beta 1$ (C-509T) polymorphism was significantly associated with an increased risk of fibrosis, whereas the XRCC1 (R399Q) polymorphism was significantly associated with an increased risk of telangiectasia. No significant genetic association was observed between atrophy and genotype (data not shown).

As the $15 \mathrm{~Gy}$ boost also appears to increase the risk of telangiectasia (Table 2), the XRCC1 (R399Q) association was performed excluding those patients who had received a boost $(n=75)$ to determine whether the two risk factors were distinct.

Table 4 Variant allele frequencies in the breast cancer patients

\begin{tabular}{lcc}
\hline SNP & $\begin{array}{c}\text { Variant allele } \\
\text { frequency }\end{array}$ & $\begin{array}{c}\text { Hardy-Weinberg } \\
(\boldsymbol{P})\end{array}$ \\
\hline TGF $\beta$ - I C-509T & 0.33 & 0.22 \\
XRCCI R399Q & 0.37 & 0.51 \\
APE-I DI26E & 0.34 & 0.39 \\
DHFR (del) & 0.46 & 0.35 \\
CX3CR I G745A & 0.28 & 0.88 \\
Hyl-I YII3H & 0.33 & 0.25 \\
MS A2756G & 0.23 & 0.09 \\
MTHFR C667T & 0.33 & 0.61 \\
\hline
\end{tabular}

Similarly, an acute reaction to radiotherapy and the TGF $\beta 1$ C-509T polymorphism increase the risk of fibrosis (Table 3 ), so patients who manifested an acute response were excluded to separate the two potentially distinct risk factors.

As shown in Table 6, there is a statistically significant excess of XRCC1 R399Q RQ heterozygotes in patients with telangiectasia $(P=0.01 ; G$-test), and an excess of TT homozygotes in patients with fibrosis $(P=0.003$; $G$-test), suggesting that the risk of telangiectasia and fibrosis as late normal tissue injury phenotypes is determined by multiple independent factors.

A boost and the XRCC1 (R399Q) polymorphism each contribute to the risk of telangiectasia, whereas an acute reaction and the TGF $\beta 1$ (C-509T) polymorphism make independent contributions to the overall risk of fibrosis. Significantly, although the risk of fibrosis and atrophy are both associated with an early acute response to radiotherapy (Table 3), atrophy was not associated with either the XRCC1 (R399Q) or TGFB1 (C-509T) polymorphisms, evidence that additional distinct genetic risk factors underlie the risk of atrophy as a late radiation injury phenotype.

The reduced sample size reduces the statistical power of any association, so the results are at best suggestive and require independent confirmation.

\section{Combined TGF $\beta 1$ (C-509T) analyses}

Quarmby et al (2003), first reported a significant association between the TGF $\beta 1$ (C-509T) polymorphism in Caucasian breast cancer patients who had received a similar radiotherapy dose (40 Gy in 15 fractions) to those used in this study (Table 1). Fibrosis was also scored using the SOMA scales, so the two studies are very similar. Quarmby et al (2003) compared patients with fibrosis $(n=14$; SOMA $2-4)$ to patients without fibrosis $(n=87$; SOMA 0), and our data for the SOMA fibrosis scores can also be divided into those that clearly show no fibrosis (score $0 ; n=115$ ) and those that unambiguously show signs of fibrosis (scores $2-4$; $n=20$ ). The data for the two studies were therefore combined to significantly increase the number of patients analysed $(n=236$; Table 7).

Table 5 Genetic association of the SOMA fibrosis and telangiectasia scores

\begin{tabular}{|c|c|c|c|}
\hline & \multicolumn{3}{|c|}{ G-test. Fibrosis } \\
\hline & $P$ & Scores compared & Patient number \\
\hline \multirow[t]{3}{*}{ TGF $\beta$ I C509T } & $\begin{array}{l}0.0041 \\
0.0032\end{array}$ & $\begin{array}{c}0 \text { vs } 2-4 \\
0-1 \text { vs } 2-4\end{array}$ & $\begin{array}{l}115 \text { vs } 20 \\
147 \text { vs } 20\end{array}$ \\
\hline & \multicolumn{3}{|c|}{ G-test. Telangiectasia } \\
\hline & $P$ & Scores compared & Patient number \\
\hline XRCCI 399 & $\begin{array}{l}0.01 \\
0.006\end{array}$ & $\begin{array}{c}0 \text { vs } 2-4 \\
0-1 \text { vs } 2-4\end{array}$ & $\begin{array}{l}111 \text { vs } 39 \\
128 \text { vs } 39\end{array}$ \\
\hline
\end{tabular}

Table 6 Genotype distributions for fibrosis and telangiectasia excluding patients that received a boost, or manifested an early acute reaction

Telangiectasia: patients who did not receive a boost $\mathrm{XRCCI}$ (R399Q) genotype
Fibrosis: patients who did not show an acute reaction TGFBI (C-509T) genotype

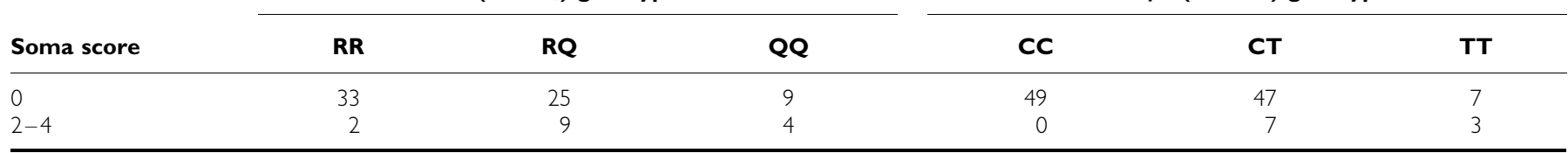


Table 7 Combined analysis of the TGF $\beta$ / (C-509T) polymorphism and fibrosis

\begin{tabular}{|c|c|c|c|c|c|c|}
\hline \multirow[b]{2}{*}{ C-509T genotype } & \multicolumn{2}{|c|}{ Quarmby et al, 2003 (patients) } & \multicolumn{2}{|c|}{ This study - Table 4 (patients) } & \multicolumn{2}{|c|}{ Combined (patients) } \\
\hline & No fibrosis & Fibrosis & No fibrosis & Fibrosis & No fibrosis & Fibrosis \\
\hline CT & 40 & 5 & 54 & 14 & 94 & 19 \\
\hline$\pi$ & 2 & 5 & 8 & 4 & 10 & 9 \\
\hline
\end{tabular}

Table 8 Risk of fibrosis according to TGF $\beta$ I genotype

\begin{tabular}{lcll}
\hline & Odds ratio & $\mathbf{9 5 \%} \mathbf{~ C l}^{\mathbf{a}}$ & \multicolumn{1}{c}{$\boldsymbol{P}$} \\
\hline CC vs (CT+TT) & 3.06 & $1.7-5.3$ & 0.00006 \\
(CC +CT) vs TT & 7.27 & $2.4-21.8$ & 0.00005 \\
CC vs TT & 14.7 & $3.8-60.3$ & 0.000003 \\
CT vs TT & 4.45 & $1.4-14.0$ & 0.007 \\
CC vs CT & 3.3 & $1.2-9.7$ & 0.002 \\
\hline
\end{tabular}

${ }^{a} 95 \%$ confidence intervals.

The combined data (Tables 7 and 8) reveal a highly significant association $(P=0.00006)$ with an OR of 3.06 (95\% CI: $1.74-5.3)$ for patients carrying at least one variant allele (CT or TT) compared with the homozygous wild-type CC genotype, and therefore this increased risk applies to $\sim 56 \%(132 / 236)$ of breast cancer patients. Furthermore, the $8 \%$ of patients that are homozygous for the variant allele (TT) carry a much higher risk of fibrosis than CC homozygotes (OR 14.7; 95\% CI 3.8-60.3) and a lesser but still significant increased risk compared with CT heterozygotes (OR 4.45 ; 95\% CI 1.4-14). Together with the observation that CT heterozygotes have a 3.3-fold increased risk of fibrosis than CC homozygotes, it suggests that the increased risk with each variant allele is additive.

\section{DISCUSSION}

Late normal tissue injury in breast cancer patients that have received standard radiotherapy treatment $(40-50 \mathrm{~Gy})$ using isoeffective fractionated schedules, with or without an additional $15 \mathrm{~Gy}$ boost, is a combination of phenotypes with distinct underlying causes. For example, the risk of telangiectasia appears to increase if the patient received a $15 \mathrm{~Gy}$ boost and this has been self-evident in the clinic as the telangiectasia is usually confined to the area of the breast that received the boost. However, there are also dose-independent genetic risk factors as evidenced by the association of the XRCC1 (R399Q) DNA repair gene polymorphism with increased risk of telangiectasia irrespective of the patient having received a boost. Similarly, the risk of fibrosis appears to increase if an early acute radiation reaction is observed with 90 days of therapy, but the TGF $\beta 1$ (C-509T) variant allele is another major independent genetic contributor to the risk of fibrosis as a late radiation injury phenotype. Atrophy is also associated with an early acute radiation response, but as atrophy is not associated with any of the QTG analysed, including XRCC1 (R399Q) or TGF 1 (C-509T), the identity of the variant gene(s) that predispose patients to atrophy as a distinct radiation injury phenotype is unknown. Similarly, the contribution of different chemotherapeutic regimes to risk of late tissue injury could not be addressed in this study.

Breast cancer is the most common female cancer in the UK and the prevalence of radiotherapy treatment in this disease is high. In 2000 , there were 40470 new cases of this disease in women and it is estimated that the lifetime risk of women in the UK developing breast cancer is $1: 9$ (CRUK, 2004). Radiotherapy substantially reduces the risk of local recurrence after surgery with a more modest reduction in cancer mortality offset by an increase in contralateral breast cancer and cardiac disease, which is more marked in older trials (EBCTCG, 2005). Virtually, all patients treated by breast conservation and patients with high risk factors for local recurrence after mastectomy receive radiotherapy. A significant proportion ( $44 \%$ in this study) of patients nevertheless remains at risk of recurrence and therefore receive an additional $15 \mathrm{~Gy}$ electron boost. Although these therapy schedules have significantly increased long-term survival, normal tissue radiation injury lasts a lifetime and is therefore increasingly a factor that must be considered in treatment choice as it can affect quality of life.

Telangiectasia in most cases is only unsightly. However, fibrosis is often associated with painful tender breasts as evidenced by the significant association of fibrosis and pain in this group of patients $(P=0.003$; data not shown). It is noteworthy that although the severity of pain rarely exceeds discomfort ameliorated by simple analgesia, these symptoms are likely to be life-long and affect quality of life. It is possible that some patients with a high-risk genotype that predisposes them to late radiation effects could avoid radiotherapy. In other cases, the advantages of radiotherapy may outweigh the risks of fibrosis and discomfort and such patients may need to be warned of the benefits and additional risks associated with radiotherapy.

Quarmby et al (2003) originally reported an association of the $T G F \beta 1$ (C-509T) gene promoter polymorphism and increased risk of fibrosis as a late radiotherapy injury phenotype. We have combined the data in both studies (Tables 7 and 8) to more than double both the total number of patients analysed $(n=236)$ and the number of patients with fibrosis $(n=38)$. This combined analysis revealed a highly significant three-fold increased risk of fibrosis following radiotherapy if a breast cancer patient carries at least one variant TGF $\beta 1(-509 \mathrm{~T})$ allele $(P=0.00006)$ and this applies to over $50 \%$ of breast cancer patients. Approximately $8 \%$ of breast cancer patients are homozygous (TT) for the variant allele and they have a 15 fold increased risk of fibrosis $(P=0.000003)$ compared to patients that are homozygous for the wild-type allele (CC). Together with any evidence of an early acute response to radiotherapy, a patient's TGF $\beta 1(-509)$ genotype might be useful in predicting the risk of fibrosis in the long term in a significant number of patients.

One recent study could not replicate the TGF $\beta 1(-509)$ SNP association with fibrosis in a retrospective analysis of breast cancer patients (Andreassen et al, 2003, 2005, 2006). The reason is unclear although differences in the two Danish studies (and the UK studies; Table 7) include the fact that all patients in the latter Danish 2006, study had mastectomies, were specifically selected retrospectively because they exhibited fibrosis, and were treated with higher radiation doses per fraction than the original 2005 study, which used changes in breast appearance as the phenotype. Thirteen percent of Danish breast cancer patients in the 2006 study carried the TT genotype (Andreassen et al, 2006), which is higher than in the UK breast cancer patients as a whole (7-9\%, Table 7), but lower than the $26 \%$ of the UK patients that were positive for 
both fibrosis and the TT genotype (Table 7). Thus, the higher fraction doses used in a significant proportion of the Danish patients in the 2006 report may be masking any genetic contribution. Furthermore, as the Danish patients were specifically selected in a retrospective study (2006), because they exhibited fibrosis as a late radiation injury, their genotype distribution cannot be combined with the UK studies (Table 7) where only a very small proportion of patients were selected and the majority of patients exhibited no late effects (Tables 2-6) (Quarmby et al, 2003). The precise patient genotype frequencies are not given in the Danish 2005 publication (Andreassen et al, 2005), so the data as published cannot be compared or combined with the UK studies. Nevertheless, if the patient genotypes were available from the 2005 study, which compares affected $(n=26)$ and unaffected $(n=26)$ patients who received 39-50 Gy total dose, they could be pooled with the UK data, as the experimental designs are so similar.

The observed contributions to fibrosis risk of an early severe acute reaction, which can trigger an inflammatory response, and the TGFB1 (C-509T) SNP, which has been associated with increased serum levels of the pro-inflammatory TGF $\beta 1$ cytokine following radiotherapy, are consistent with the established link between fibrosis and inflammation (Awad et al, 1988; Zugmaier et al, 1991; Anscher et al, 1997; Martin et al, 1997, 2000; Grainger et al, 1999; Li et al, 1999). Additional genetic factors are presumably responsible for the radiosensitivity that causes the severe acute reaction and a number of variant genes have been implicated in abnormal cell radiosensitivity (Moullan et al, 2003; Chang-Claude et al, 2005; De Ruyck et al, 2005; Fernet and Hall, 2005), but none of the eight candidate gene SNP analysed in this study was significantly associated with an early acute reaction. The observed increased risk of telangiectasia in patients, who received an additional $15 \mathrm{~Gy}$ boost and/or are deficient in DNA repair owing to the inheritance of a variant XRCC1 (R399Q) allele, is consistent with the association of telangiectasia with vascular endothelial cell damage (Quarmby et al, 1999).

Multiple testing has been performed on the same patient samples so false positive or negative results are likely. As the association between fibrosis and the TGF $\beta 1(-509)$ polymorphism in breast cancer patients is a confirmation of previous independent analyses (Quarmby et al, 2003; Andreassen et al, 2005), the Boniferroni correction factor does not apply in this case, but the association would still be significant $(P<0.05)$ if the correction factor was applied, as it would be for the association between XRCC1 (R399Q) and telangiectasia. Nevertheless, the number of patients assessed is relatively small, so further analyses using an independent cohort of breast cancer patients are required to confirm the apparent association between an early acute reaction and late fibrosis/atrophy, and between the additional $15 \mathrm{~Gy}$ boost, XRCC1 (R399Q) and telangiectasia.

\section{ACKNOWLEDGEMENTS}

Thanks to Dr S Chan and D Morgan of City Hospital Nottingham for allowing their patients to be examined in this study, and thanks to $C$ Talbot and G Thomas for help during the course of this study. GG was supported by a HOPE Foundation for Cancer Research studentship.

\section{REFERENCES}

Andreassen CN, Alsner J, Overgaard J, Herskind C, Haviland J, Owen R, Homewood J, Bliss J, Yarnold J (2005) TGFB1 polymorphisms are associated with risk of late normal tissue complications in the breast after radiotherapy for early breast cancer. Radiother Oncol 75: 18-21

Andreassen CN, Alsner J, Overgaard M, Overgaard J (2003) Prediction of normal tissue radiosensitivity from polymorphisms in candidate genes. Radiother Oncol 69: 127-135

Andreassen CN, Alsner J, Overgaard M, Sorensen FP, Overgaard J (2006) Risk of radiation-induced subcutaneous fibrosis in relation to single nucleotide polymorphisms in TGFB1, SOD2, XRCC1, XRCC3, APEX and ATM - a study based on DNA from paraffin embedded tissue samples. Int J Radiat Biol 82: 577 - 586

Anscher MS, Kong FM, Marks LB, Bentel GC, Jirtle RL (1997) Changes in plasma transforming growth factor beta during radiotherapy and the risk of symptomatic radiation-induced pneumonitis. Int J Radiat Oncol Biol Phys 37: $253-258$

Awad MR, El-Gamel A, Hasleton P, Turner DM, Sinnott PJ, Hutchinson IV (1988) Genotypic variation in the transforming growth factor-betal gene: association with transforming growth factor-betal production, fibrotic lung disease, and graft fibrosis after lung transplantation. Transplantation 66: $1014-1020$

Bartelink H, Horiot JC, Poortmans P, Struikmans H, Van den Borger W, Jager J, Hoogenraad W, Collette L, Pierart M, for the European Organization for Research and Treatment of Cancer, Radiotherapy and Breast Cancer Groups (2001) Recurrence rates after treatment of breast cancer with standard radiotherapy with or without additional radiotherapy. $N$ Eng J Med 345: 1378-1387

Bentzen SM, Dorr W, Anscher MS, Denham JW, Hauer-Jensen M, Marks LB, Williams J (2003) Normal tissue effects: reporting and analysis. Sem Radiat Oncol 13: $189-202$

Bentzen SM, Overgaard M (1991) Relationship between early and late normal-tissue injury after postmastectomy radiotherapy. Radiother Oncol 20: $159-165$

Bentzen SM, Overgaard M, Overgaard J (1993) Clinical correlations between late normal tissue endpoints after radiotherapy: implications for predictive assays of radiosensitivity. Eur J Cancer 29A: 1373-1376
Brem R, Cox DG, Chapot B, Moullan N, Romestaing P, Gerard JP, Pisani P, Hall J (2006) The XRCC1 $-77 \mathrm{~T}>\mathrm{C}$ variant: haplotypes, breast cancer risk, response to radiotherapy and the cellular response to DNA damage. Carcinogenesis 27: 2469-2474

Chang-Claude J, Popanda O, Tan X-L, Kropp S, Helmbold I, von Fournier D, Hasse W, Sautter-Bihl ML, Wenz F, Schmezer P, Ambrosone CB (2005) Association between polymorphisms in the DNA repair genes, $X R C C 1$, APE1 and XPD and acute side effects of radiotherapy in breast cancer patients. Clin Cancer Res 11: $4802-4809$

Clouthier DE, Comerford SA, Hammer RE (1997) Hepatic fibrosis, glomerulosclerosis, and a lipodystrophy-like syndrome in PEPCK-TGFbetal transgenic mice. J Clin Invest 100: 2697-2713

Cox JD, Stetz J, Pajak TF (1995) Toxicity criteria of the Radiation Therapy Oncology Group (RTOG) and the European Organization for Research and Treatment of Cancer (EORTC). Int J Radiat Oncol Biol Phys 31: $1341-1346$

CR-UK: Cancer Research UK (2004) Cancer Monographs. In Toms JR (ed) De Ruyck K, Van Eikeren M, Claes K, Bacher K, Vral A, de Neve W, Thierens $H$ (2006) TGFb1 polymorphisms and late clinical radiosensitivity in patients treated for gynecologic tumors. Int J Radiat Oncol Biol Phys 65: $1240-1248$

De Ruyck K, Van Eikeren M, Claes K, Morthier R, De Paepe A, Vral A, De Ridder L, Thierens H (2005) Radiation-induced damage to normal tissues after radiotherapy in patients treated for gynecologic tumors: association with single nucleotide polymorphisms in XRCC1, XRCC3, and OGG1 gene and in vitro chromosomal radiosensitivity in lymphocytes. Int J Radiat Oncol Biol Phys 62: 1140-1149

EBCTCG: Early Breast Cancer Trialists' Collaborative Group (2005) Effects of radiotherapy and of differences in the extent of surgery for early breast cancer on local recurrences after 15 year survival; an overview of the randomised trials. Lancet 366: $2087-2106$

El-Gamel A, Awad MR, Hasleton PS, James Hutchinson J, Yonan N, Egan J, Colin Campbell C, Rahman A, Sheldon S, Deiraniya A, Ian V, Hutchinson IV (1999) Transforming growth factor-beta (TGFbeta1) genotype and lung allograft fibrosis. J Heart Lung Transplant 18: $517-523$ 
Fernet M, Hall J (2005) Genetic markers of therapeutic radiation sensitivity. DNA Repair 3: $1237-1243$

Fiets WE, van Helvoirt RP, Nortier JWR, van der Tweel I, Struikmans H (2003) Acute toxicity of concurrent adjuvant radiotherapy and chemotherapy (CMF or $\mathrm{AC}$ ) in breast cancer patients: a prospective, comparative, non-randomised study. Eur J Cancer 39: 1081 - 1088

Gauldie J, Galt T, Bonniaud P, Robbins C, Kelly M, Warburton D (2003) Transfer of the active form of transforming growth factor-beta 1 gene to newborn rat lung induces changes consistent with bronchopulmonary dysplasia. Am J Pathol 163: 2575-2584

Grainger DJ, Heathcote K, Chiano M, Snieder H, Kemp PR, Metcalfe JC, Carter ND, Tim D, Spector TD (1999) Genetic control of the circulating concentration of transforming growth factor type betal. Hum Mol Genet 8: $93-97$

Hu JJ, Smith TR, Miller MS, Mohrenweiser HW, Golden A, Case LD (2001) Amino acid substitution variants of APE1 and XRCC1 genes associated with ionizing radiation sensitivity. Carcinogenesis 22: 917-922

Johnson WG, Stenroos ES, Spychala JR, Chatkupt S, Ming SX, Buyske S (2004) New $19 \mathrm{bp}$ deletion polymorphism in intron-1 of dihydrofolate reductase (DHFR): a risk factor for Spina Bifida acting in mothers during pregnancy? Am J Med Genetics 124: 339-345

Lebailly P, Willett EV, Moorman AV, Roman E, Cartwright R, Morgan GJ, Wild CP (2002) Genetic polymorphisms in microsomal epoxide hydrolase and susceptibility to adult acute myeloid leukaemia with defined cytogenetic abnormalities. Br J Haematol 116: 587-594

Li C, Wilson PB, Levine E, Barber J, Stewart AL, Kumar S (1999) TGF-betal levels in pre-treatment plasma identify breast cancer patients at risk of developing post-radiotherapy fibrosis. Int J Cancer 84: 155-159

Linnebank M, Schmidt S, Kolsch H, Linnebank A, Heun R, Schmidt-Wolf IGH, Glasmacher A, Fliessbac AK, Klockgether T, Schlegel U, Pels H (2004) The methionine synthase polymorphism D919G alters susceptibility to primary central nervous system lymphoma. Br J Cancer 90: 1969-1971

Martin M, Lefaix J, Delanian S (2000) TGF-betal and radiation fibrosis: a master switch and a specific therapeutic target? Int J Radiat Oncol Biol Phys 47: 277-290

Martin M, Vozenin MC, Gault N, Crechet F, Pfarr CM, Lefaix JL (1997) Coactivation of AP-1 activity and TGF-betal gene expression in the stress response of normal skin cells to ionizing radiation. Oncogene 15: 981-989

Mauch C, Kreig T (1990) Fibroblast-matrix interactions and their role in the pathogenesis of fibrosis. Rheum Dis Clin North Am 16: 93-107

McDermott DH, Halcox JPJ, Schenke WH, Waclawiw MA, Merrell MN, Epstein N, Quyyumi AA, Murphy PM (2001) Association between polymorphism in the chemokine receptor CX3CR1 and coronary vascular endothelial dysfunction and atherosclerosis. Circ Res 89: $401-407$

Moullan N, Cox DG, Angele S, Romestaing P, Gerard JP, Hall J (2003) Polymorphisms in the DNA repair gene XRCC1, breast cancer risk, and response to radiotherapy. Cancer Epidemiol Biomarkers Prev 12: 1168 1174

NCRN Trial Standardisation of Breast Radiotherapy (1998) Clinical Trials and Statistics Unit. Sutton, Surrey, UK: Institute of Cancer Research

O'Sullivan B, Levin W (2003) Late radiation-related fibrosis: pathogenesis, manifestations, and current management. Semin Radiat Oncol 13: $274-$ 289

Pavy JJ, Denekamp J, Letschert J, Littbrand B, Mornex F, Bernier J, Gonzales-Gonzales D, Horiot JC, Bolla M, Bartelink H (1995) Late effects toxicity scoring: the SOMA scale. Radiother Oncol 35: 11-15

Quarmby S, Fakhoury H, Levine E, Barber J, Wylie J, Hajeer AH, West C, Stewart A, Magee B, Kumar S. (2003) Association of transforming growth factor beta-1 single nucleotide polymorphisms with radiation-induced damage to normal tissues in breast cancer patients. Int J Radiat Biol 79: $137-143$

Quarmby S, Kumar P, Kumar S (1999) Radiation-induced normal tissue injury: role of adhesion molecules in leukocyte-endothelial cell interactions. Int J Cancer 82: 385-395

Randall K, Coggle JE (1995) Expression of transforming growth factor-beta 1 in mouse skin during the acute phase of radiation damage. Int J Radiat Biol 68: $301-309$

Sanderson N, Factor V, Nagy P, Kopp J, Kondaiah P, Wakefield L, Roberts AB, Sporn MB, Thorgeirsson SS (1995) Hepatic expression of mature transforming growth factor beta 1 in transgenic mice results in multiple tissue lesions. Proc Natl Acad Sci USA 92: 2572-2576

Shanley S, McReynolds K, Ardern-Jones A, Ahern R, Fernando I, Yarnold J, Evans G, Eccles D, Hodgson S, Ashley S, Ashcroft L, Tutt A, Bancroft E, Short S, Smith I, Gui G, Barr L, Baaildam A, Howell A, Royle G, Easton D, Eeeles R (2006) Acute chemotherapy-related toxicity is not increased in BRCA1 and BRACA2 mutation carriers treated for breast cancer in the United Kingdom. Clin Cancer Res 12: 7033 - 7038

Sokal RR, Rohlf FJ (1995) In Biometry, 3rd edn, New York, USA: W.H. Freeman and Company

Terrell TG, Working PK, Chow CP, Green JD (1993) Pathology of recombinant human transforming growth factor-beta 1 in rats and rabbits. Int Rev Exp Pathol 34: 43-67

Van der Kogel AJ (1993) Radiobiology of normal tissues. In Basic Clinical Radiobiology Steel GG (ed) pp 99-107, London: Arnold

Zugmaier G, Paik S, Wilding G, Knabbe C, Bano M, Lupu R, Deschauer B, Simpson S, Dickson RB, Lippman M (1991) Transforming growth factor beta 1 induces cachexia and systemic fibrosis without an antitumor effect in nude mice. Cancer Res 51: 3590 - 3594 